\title{
Structure Modelling of Subsurface by using Kirchhoff Migration Method and Finite Difference Anisotropy Method
}

\author{
Husni Cahyadi Kurniawan ${ }^{1 *}$, Adi Susilo ${ }^{1}$, dan Teguh Suroso ${ }^{2}$ \\ ${ }^{1}$ Jurusan Fisika, Fakultas MIPA, Universitas Brawiijaya, Malang \\ ${ }^{2}$ Senior Geophysics Pertamina UTC \\ 1*Email: huznie.kurniawan@gmail.com
}

DOI: http://dx.doi.org/10.13057/ijap.v6i02.1422

\begin{abstract}
The image of subsurface with a migration method keeps on developing to get an image result which the closest in real condition. The conditions in subsurface are very complex and variables it couses the process of wave propagation which can not be judged as the same in every layers. So it is needed an anisotropy pharameter analysiz $(\eta)$ in seismic data migration process. The research will compare two kinds of migrations those are Kirchhoff migration and finite difference anisotropy. It is done because not all datas are processed by anisotropy, even with isotropi it will get good result. The result of kirchoff migration has not so good quality (low resolution) on the first layer reflector.but on the second and third layer reflector have good result (high resolution). I estimate that in the first layer reflector there is anistropi influence, because the ratio effect between far offset and the depth is hight. The analysis result get $\eta$ ansotropi pharameter result as 0.25 and put into migration process. On the second migration process is finite difference anisotropy appears on the first layer reflector and shows high resolution and suitable with the real layer model.
\end{abstract}

Keywords: Anistropi parameter, Kirchhoff migration, finite difference anistropy;

\section{ABSTRAK}

Pencitraan bawah permukaan dengan metode migrasi terus dikembangkan untuk memperoleh hasil citra yang paling mendekati kondisi sebenarnya. Kondisi bawah permukaan bumi yang sangat komplek dan bervariasi menyebabkan proses penjalaran gelombang tidak dapat dianggap sama di setiap lapisan, sehingga perlu analisis parameter anisotropi $(\eta)$ dalam proses migrasi data seismik. Penelitian ini akan membandingkan dua migrasi yaitu migrasi Kirchhoff dan migrasi anisotropi beda hingga. Hal ini dilakukan karena tidak semua data perlu diproses dengan anisotropi, bahkan dengan isotropi pun hasilnya sudah menunjukkan bagus. Hasil pengolahan dengan migrasi Kirchhoff memiliki kualitas kurang bagus (resolusi rendah) pada reflektor lapisan pertama, sedangkan untuk reflektor lapisan kedua dan ketiga hasilnya bagus (resolusi tinggi). Diduga pada reflektor lapisan pertama ada pengaruh nilai anistropi, karena efek rasio antara far offset dan kedalam sangat tinggi. Hasil analisis didapatkan nilai parameter anisotropi eta sebesar 0,25 yang kemudian dimasukkan pada proses migrasi. Pada proses migrasi yang kedua yaitu dengan migrasi anisotropi beda hingga tampak pada reflektor lapisan pertama hasilnya menunjukkan resolusi tinggi dan sesuai dengan model perlapisan sebenarnya.

Kata Kunci: Parameter anisotropi, migrasi Kirchhoff, migrasi anisotropi beda hingga

\section{PENDAHULUAN}

Metode seismik sampai hari ini merupakan metode yang paling dominan dipakai dalam eksplorasi hidrokarbon. Kelebihan metode ini dibandingkan dengan metode lainnya yaitu 
memiliki akurasi dan resolusi yang tinggi serta penetrasi ke dalam bumi besar, sehingga memberikan gambaran bawah permukaan bumi yang lebih terperinci. Metode seismik yang sering digunakan dalam dunia eksplorasi adalah metode seismik refleksi, hal ini karena kemampuan dari gelombang seismik refleksi bisa mencapai ribuan meter. Kemampuannya dalam mendeteksi lapisan bawah permukaan yang begitu dalam sangat dibutuhkan dalam dunia eksplorasi. Metode seismik refleksi memiliki kemampuan untuk menembus lapisan bumi sampai ribuan meter, Oleh sebab itu processing data seismik disini sangat berperan penting, untuk menghasilkan citra yang memiliki S/N ratio (perbandingan sinyal dengan noise) tinggi dan resolusi yang sangat tinggi.

Processing data seismik memiliki beberapa tahapan, dari begitu banyak tahapan yang harus dilakukan maka ada salah satu tahapan yang penting yakni tahapan migrasi seismik. Migrasi data seismik adalah suatu proses untuk memetakan suatu penampang dengan cara eventevent seismik dikembalikan posisinya pada tempat dan waktu yang sesuai. Tujuan migrasi seismik untuk meningkatkan resolusi lateral dengan menghilangkan efek difraksi pada titiktitik diskontinuitas/ patahan ${ }^{[7]}$.

Migrasi dalam penelitian ini dilakukan untuk mengembalikan reflektor ke posisi semula, sehingga diharapkan hasil dari migrasi ini sesuai dengan kondisi bawah permukaan yang sebenarnya sehingga memberikan gambaran bawah permukaan yang sesuai dengan kondisi aslinya. Proses migrasi seismik umumnya dilakukan dengan metode migrasi isotropi namun untuk data yang memiliki nilai parameter anisotropi menunjukkan anomali pada far offset. Anomali ini bisa terjadi ketika selisih antara kedalaman $(d)$ dengan far offset $(x)$ terlalu besar. Proses migrasi anistropi ini memang sangat jarang di lakukan dalam perusahaan, karena dalam ekplorasi sangat jarang sekali terjadi perbedaan terlalu besar antara kedalaman dan far offset.

Migrasi seismik memiliki banyak metode, dalam penilitian ini melakukan dua metode yaitu migrasi Kirchhoff dan anistropi beda hingga. Migrasi Kirchhoff sendiri di gunakan untuk mengetahui hasil pencitraan tanpa memasukkan parameter anistropi, sedangkan untuk metode anistropi beda hingga memasukkan nilai parameter anistropi. Metode anistropi beda hingga di pilih karena memiliki menghasilkan noise migrasi yang kecil, efektif untuk daerah dengan rasio s/n (signal to noise ratio) rendah ${ }^{[5]}$. Kedua metode ini digunakan untuk mengetahui perbandingan hasil pencitraannya

\section{METODE}

Penelitian kali ini menggunakan model data sintetik untuk memudahkan menganilisis efek ansitropi dan hasil migrasi. Data sintetik ini memiliki akuisisi data sempurna dan sedikit noise, sehingga nanti fokus pada migrasi tanpa melakukan proses filter. Penelitian ini melakukan dua kali proses mirgrasi, yakni Kirchhoff dan anisotropi beda hingga.

\section{Migrasi Kirchhoff}

Migrasi Kirchhoff pada dasarnya merupakan prosedur penjumlahan difraksi. Pada tempattempat zero offset kurva difraksi berbentuk hiperbolik adapun travel time yang digunakan

$$
t_{x}=\sqrt{t_{o}{ }^{2}+\frac{x^{2}}{v_{m i g}{ }^{2}}}
$$


Berdasarkan persamaan di atas $t_{x}$ adalah selang waktu untuk jarak x (s), $t_{o}$ adalah selang waktu pada zero offset (s), $x$ adalah jarak trace atau jarak antara sumber ledakan dan geophone $(\mathrm{m}), v_{\text {mig }}$ adalah kecepatan gelombang untuk migrasi $(\mathrm{m} / \mathrm{s})$.

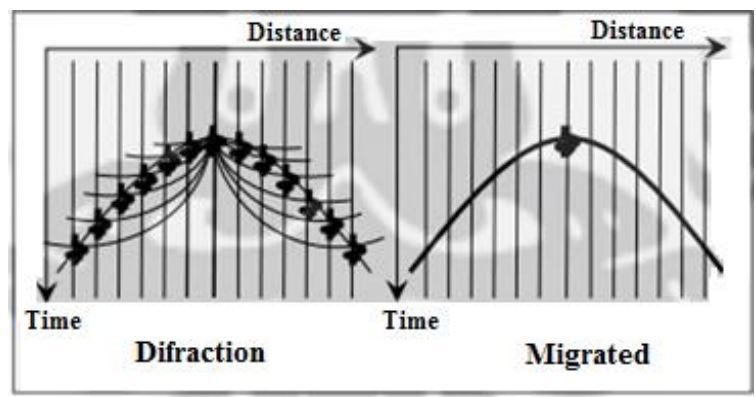

Gambar 1. Skema penjumlahan energi di puncak kurva difraksi ${ }^{[1]}$.

Migrasi Kirchhoff menjumlahkan keseluruhan titik data di sepanjang kurva difraksi Pre Stack dan memindah hasilnya ke puncak (di zero-offset) (Gambar 1). Pada migrasi dalam kawasan waktu, kecepatan migrasi dan persamaan 2 dipakai untuk menghitung permukaan difraksi, sedangkan pada migrasi dalam kawasan kedalaman, penjalaran gelombang sebenarnya (dari ray tracing) dari setiap sumber ke tiap receiver yang digunakan untuk menentukan permukaan difraksi.

$$
t_{x}=\sqrt{\left(t_{0}^{2}+\frac{\left(x_{s}+x_{r}\right)^{2}}{v_{\text {mig }}^{2}}\right)}+\sqrt{\left(t_{0}^{2}+\frac{\left(x_{s}-x_{r}\right)^{2}}{v_{\text {mig }}^{2}}\right)}
$$

Dengan $\mathrm{V}_{\text {rms }}$ adalah kecepatan rms, $\mathrm{x}_{\mathrm{s}}$ adalah posisi sumber dan $\mathrm{X}_{\mathrm{r}}$ adalah posisi receiver ${ }^{[7]}$.Adapun alur proses migrasi kirchhoff sebagai berikut.

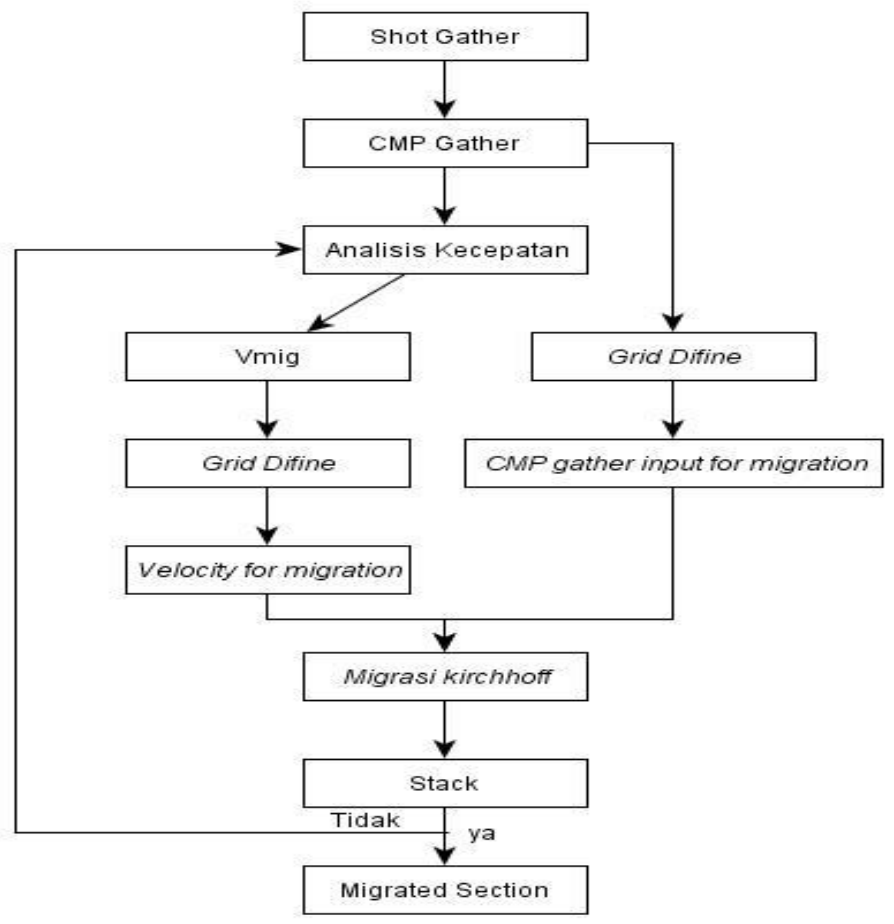

Gambar 2. Alur migrasi Kirchhoff. 
Dari gambar 2 bisa dijelaskan proses migrasi kirchoff yang utama adalah proses menginputkan dari velocity for migration dan CMP gather for migration. Data awal yang diahasilkan berupa shot gather. Shot gather ini masih memerlukan proses lagi untuk mendapatkan hasil migrasi yang di inginkan. Pertama shot gather akan diubah menjadi CMP gather, dimana CMP gather ini merupakan gabungan dari beberapa trace atau shot gather. CMP gather yang dihasilkan kemudian di analisis kecepatannya dengan menggunakan NMO dan Semblance. Dalam software yang kami gunakan, proses NMO dilakukan dengan menentukan kecepatan yang sesuai untuk perlapisan, apabila kecepatan sudah sesuai maka lapisan akan lurus. Hasil dari analisis ini merupakan kecepatan rata-rata $\left(v_{\text {mig }}\right)$ yang nantinya akan di inputkan kedalam proses migrasi. Sebelum di inputkan terlebih dahulu dirubah ke dalam 3D grid difine. Setelah di migrasi maka akan dilakukan stack untuk menggabungkan perlapisan sehingga sesuai dengan model sintetik. Hasil ahir nantinya akan dibandingkan dengan proses migrasi anisotropi beda hingga.

\section{Migrasi Anistropi Beda Hingga}

Pada migrasi jenis ini digunakan pendekatan deterministic. Prosedur migrasinya dimodelkan oleh persamaan gelombang. Persamaan tersebut kemudian didekati oleh persamaan yang lebih sederhana, dan setelah itu penyelesaiannya didekati oleh algoritma beda hingga (finite difference) ${ }^{[2]}$.Keuntungan dari metode ini ialah kenampakan yang baik bila data seismik mempunyai S/N yang rendah. Cara mendapatkan perekaman gelombang seismik yang telah dimigrasi tesebut dapat dilakukan dengan menggunakan downward continuation. Persamaan gelombang skalar untuk dua dimensi sebagai berikut.

$$
\frac{\partial^{2} \psi}{\partial x^{2}}+\frac{\partial^{2} \psi}{\partial z^{2}}=\frac{1}{v^{2}} \frac{\partial^{2} \psi}{\partial t^{2}}
$$

Rekaman data seismik menunjukan respon gelombang seismik di permukaan yang dituliskan $\mathrm{U}(\mathrm{x}, 0, \mathrm{t})$ dalam penjalarannya di bawah permukaan maka akan tercatat dan ditransformasikan menjadi $\mathrm{U}(\mathrm{x}, \mathrm{z}, 0)$. Gelombang seismik dikontinuasikan kebawah secara bertahap sampai pada reflektor.

Jika kita menganggap t adalah waktu tempuh setengah dari waktu tempuh dua arah, maka gelombang bidang merambat yang dibentuk oleh sudut $\theta$ dinyatakan oleh persamaan

$$
\psi(x, z, t)=A \exp [j \omega\{t-(x / v) \sin \theta-(z / v) \cos \theta\}]
$$

Dianggap $\theta$ sangat kecil maka $\sin \theta \approx \theta$ dan $\cos \theta \approx(11 / 2 \theta 2)$, sehingga persamaan menjadi

$$
\psi(x, z, t)=A \exp \left[j \omega\left\{t-\frac{x \theta}{v}-\frac{z}{v}+\frac{z \theta^{2}}{2 v}\right\}\right]
$$

dan

$$
\begin{aligned}
& \frac{\partial \psi}{\partial t}=\frac{\partial \psi^{*}}{\partial t^{*}} \frac{\partial t}{\partial t}=\frac{\partial \psi^{*}}{\partial t^{*}} ; \frac{\partial^{2} \psi}{\partial t^{2}}=\frac{\partial^{2} \psi}{\partial t^{* 2}} \\
& \frac{\partial \psi}{\partial x}=\frac{\partial \psi^{*}}{\partial x^{*}} ; \frac{\partial^{2} \psi}{\partial x^{2}}=\frac{\partial^{2} \psi^{*}}{\partial x^{2}}
\end{aligned}
$$




$$
\begin{aligned}
& \frac{\partial \psi}{\partial z}=\frac{\partial \psi^{*}}{\partial z^{*}}+\frac{\partial \psi^{*}}{\partial t^{*}} \frac{\partial t^{*}}{\partial z}=\frac{\partial \psi^{*}}{\partial z}-\frac{1}{v} \frac{\partial^{2} \psi^{*}}{\partial t^{*}} \\
& \frac{\partial^{2} \psi}{\partial z^{2}}=\frac{\partial^{2} \psi^{*}}{\partial z^{2}}-\frac{2}{v} \frac{\partial^{2} \psi^{*}}{\partial z \partial t^{*}}+\frac{1}{v} \frac{\partial^{2} \psi^{*}}{\partial t^{*}}
\end{aligned}
$$

Disubtitusikan ke persamaan gelombang (9) memberikan persamaan baru

$$
\frac{\partial^{2} \psi^{*}}{\partial x^{2}}+\frac{\partial^{2} \psi^{*}}{\partial z^{2}}-\frac{2}{v} \frac{\partial^{2} \psi^{*}}{\partial z \partial t^{*}}=0
$$

Persamaan gelombang yang merambat mendekati vertikal $\psi^{*}$ terhadap z sangat kecil, sehingga $\frac{\partial^{2} \psi^{*}}{\partial z^{2}}$ bisa diabaikan. Hal ini disebut dengan pendekatan $15^{\circ}$.

$$
\frac{\partial^{2} \psi^{*}}{\partial x^{2}}-\left(\frac{2}{v}\right) \frac{\partial^{2} \psi^{*}}{\partial z \partial t^{*}}=0
$$

Persamaan bentuk ini mempunyai keterbatasan dimana tidak mampu digunakan untuk melakukan migrasi terhadap kemiringan reflektor yang cukup tajam. Untuk menyelesaikan persamaan (11) digunakan finite difference, dimana $\psi^{*}$ disusun dalam bentuk array 3 dimensi dengan selang interval adalah $\Delta \mathrm{x}, \Delta \mathrm{z} . \Delta \mathrm{t}^{*}$.

$$
\begin{aligned}
& \frac{\partial^{2} \psi^{*}}{\partial x^{2}} \approx \frac{\psi^{*}\left(x, z, t^{*}\right)-2 \psi^{*}\left(x-\Delta x, z, t^{*}\right)+\psi^{*}\left(x-2 \Delta x, z, t^{*}\right)}{\Delta x^{2}} \\
& \frac{\partial^{2} \psi^{*}}{\partial z \partial t^{*}} \approx \frac{\left\{\psi^{*}\left(x, z, t^{*}\right)-\psi^{*}\left(x, z-\Delta z, t^{*}\right)+\psi^{*}\left(x, z, t-\Delta t^{*}\right)+\psi^{*}\left(x, z-\Delta z, t^{*}-\Delta t^{*}\right)\right\}}{\Delta z \Delta t^{*}}
\end{aligned}
$$

sehingga persamaanya dapat dituliskan solusi sebagai berikut

$$
\Psi^{*}\left(x, z, t^{*}\right)=\frac{\Delta z \Delta t^{*}}{2 \Delta z-V \Delta z \Delta t^{*}}\left\{\begin{array}{l}
\frac{\Psi^{*}\left(x, z-\Delta z, t^{*}\right)}{\Delta z \Delta t^{*}}+\frac{\Psi^{*}\left(x, z, t^{*}-\Delta t^{*}\right)}{\Delta z \Delta t^{*}} \\
-\frac{V \Psi^{*}\left(x-\Delta x, z, t^{*}\right)}{\Delta x^{*}}-\frac{\Psi^{*}\left(x, z-\Delta z, t^{*}-\Delta t^{*}\right)}{\Delta z \Delta t^{*}} \\
+\frac{V \Psi^{*}\left(x-2 \Delta x, z, t^{*}\right)}{2 \Delta x^{2}}
\end{array}\right\}
$$


Adapun alur proses migrasi kirchhoff sebagai berikut.

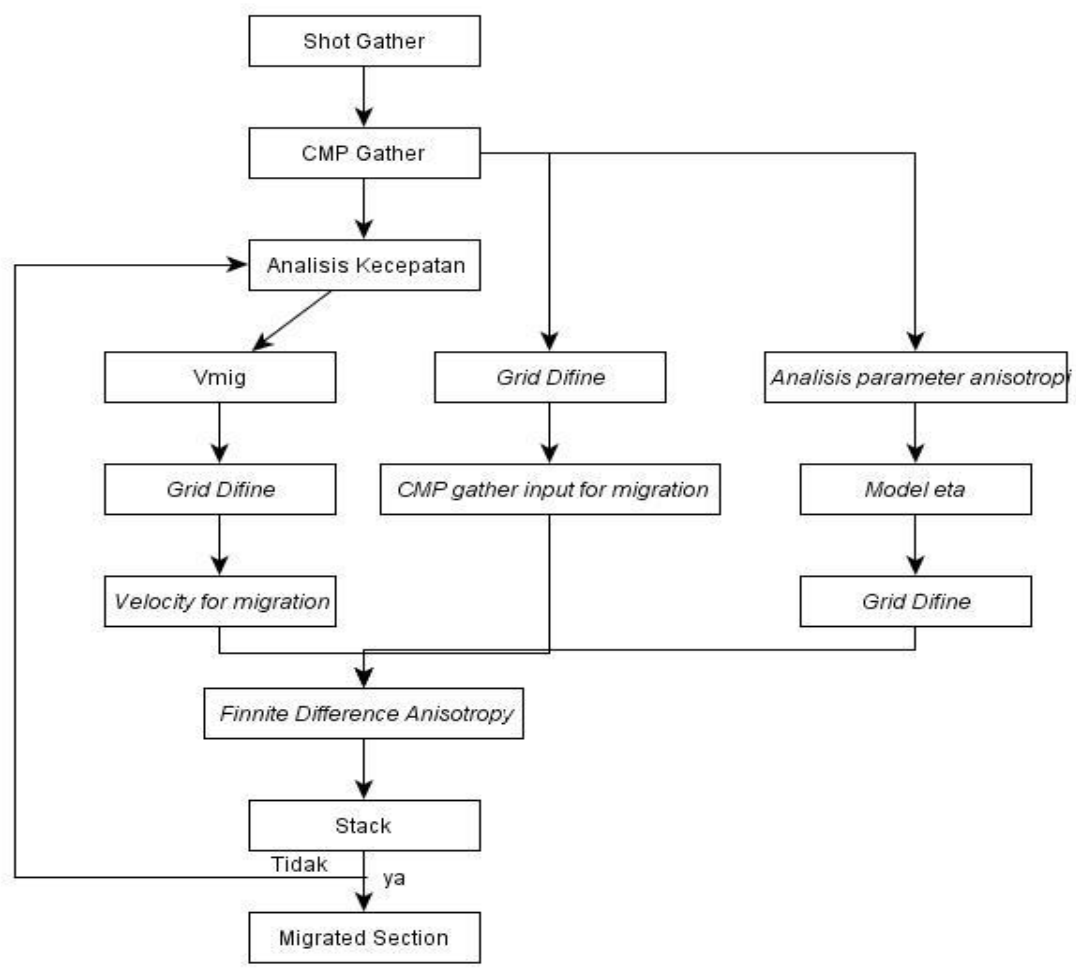

Gambar 3. Alur migrasi anistropi beda hingga.

\section{HASIL DAN PEMBAHASAN}

Data penelitian ini menggunakan data sintetik yang digunakan adalah data dengan struktur lurus, ini dimaksudkan agar efek anisotropi pada data dapat terlihat dengan jelas.

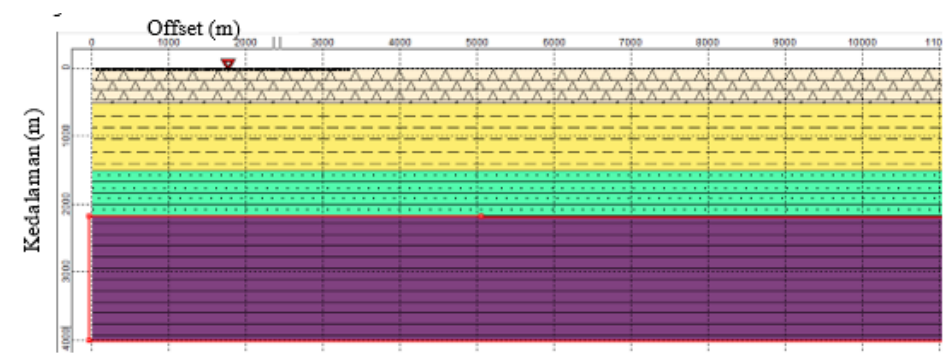

Gambar 4. (Colour Online) Model bawah permukaan

Gambar 4 menunjukkan model struktur terdiri dari 4 lapisan yang masing-masing lapisan memiliki jenis batuan dan kecepatan yang berbeda. lapisan pertama dengan kedalaman 0 $500 \mathrm{~m}$ adalah jenis batuan anhydrite (min) dengan kecepatan $1500 \mathrm{~m} / \mathrm{s}$, lapisan kedua dengan kedalaman 500 - $1500 \mathrm{~m}$ adalah jenis batuan clay (avr) dengan kecepatan $1800 \mathrm{~m} / \mathrm{s}$, lapisan ketiga dengan kedalaman 1500 - $2100 \mathrm{~m}$ adalah jenis batuan aleurolite (avr) dengan kecepatan $2400 \mathrm{~m} / \mathrm{s}$, sedangkan lapisan keempat atau terakhir dengan kedalaman 2100 4000 madalah lapisan batuan argillite (avr) dengan kecepatan $3000 \mathrm{~m} / \mathrm{s}$. Semakin kebawah nilai kecepatannya semakin besar, hal ini agar sesuai dengan keadaan geologi sebenarnya. 
Dari proses penembakan di software Tesseral didapatkan shotpoint gather. Kemudian dari shotpoint gather dilakukan pengolahan menjadi CMP gather. CMP gather adalah gabungan dari trace yang memiliki titik tengah yang sama. (Gambar 5), dalam penelitian menghasilkan 100 gather yakni sesuai dengan julah penembakan yang dilakukan . CMP gather ini yang nantinya akan di pakai untuk proses berikutnya.

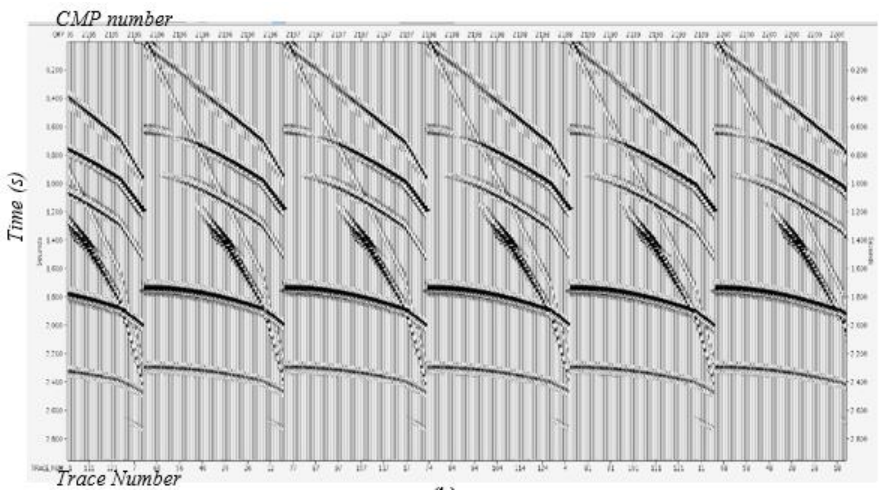

Gambar 5. Cmp Gather

Analisis parameter anistropi pada CMP gather melibatkan proses moveout nonhyperbolic, dengan memasukkan nilai $\eta$ tertentu (konstan) sampai ujung yang melengkung pada lapisan pertama menjadi lurus.
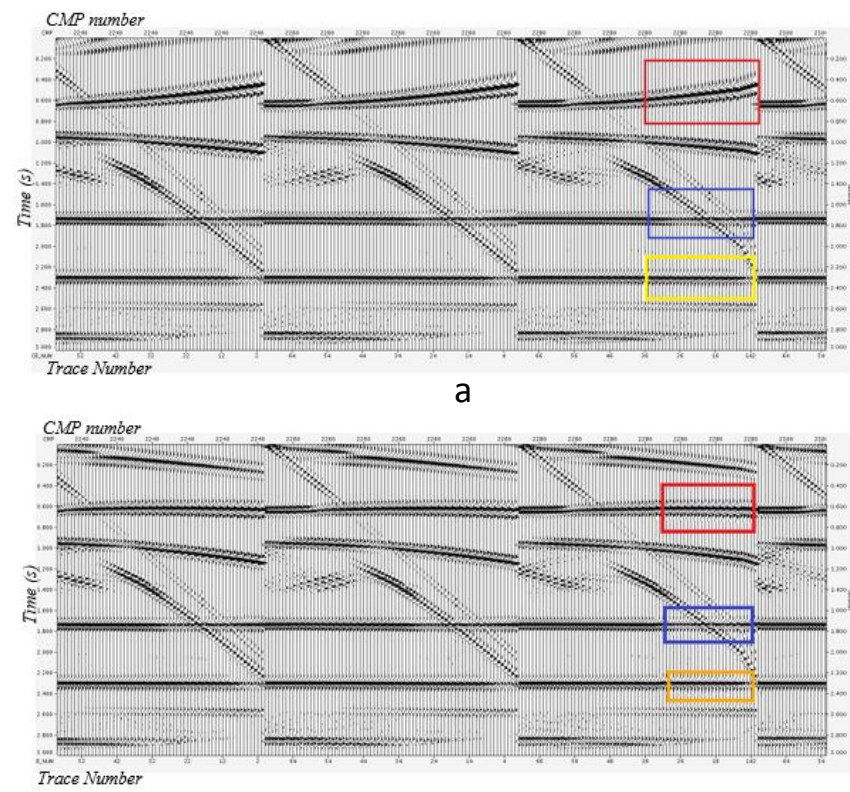

b

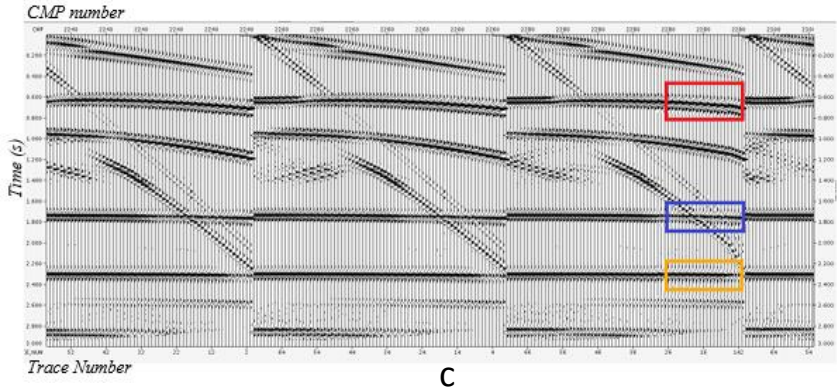

Gambar 6. (Colour Online) Analisis moveout nonhiperbolyc (a) Nilai $\eta 0,075$ (b) Nilai $\eta 0,25$ (c) Nilai $\eta 0,4$ 
Gambar 6 merupakan analisis CMP gather untuk mendapatkan nilai $\eta$. Analis $\eta$ hanya dilakukan pada lapisan yang mengalami efek anistropi, yaitu lapisan pertama (kotak merah). Lapisan pertama mengalami efek anisotropi dikarenakan besarnya kedalaman lapisan 1 hanya 500m jauh lebih kecil jika dibandingkan dengan besarnya far offset 1875,5 , pada nilai 0,075 (Gambar 6a)kondisi ujung-ujung reflektor lapisan pertama masih melengkung keatas. Sedangkan pada nilai $\eta$ 0,4 (Gambar 6c) reflektor menjadi melengkung kebawah ini menunjukkan bahwa nilai $\eta$ terlalu besar. Nilai $\eta$ yang paling efektif dan terbaik untuk digunakan adalah 0,25 (Gambar 6b), karena pada nilai $\eta$ tersebut kondisi ujung-ujung reflektor menjadi lurus atau kembali pada zero offset.

Adapun hasil proses migrasi Kirchhoff tanpa memasukkan nilai anisotropi $\eta$, menghasilkan model seperti gambar 7.

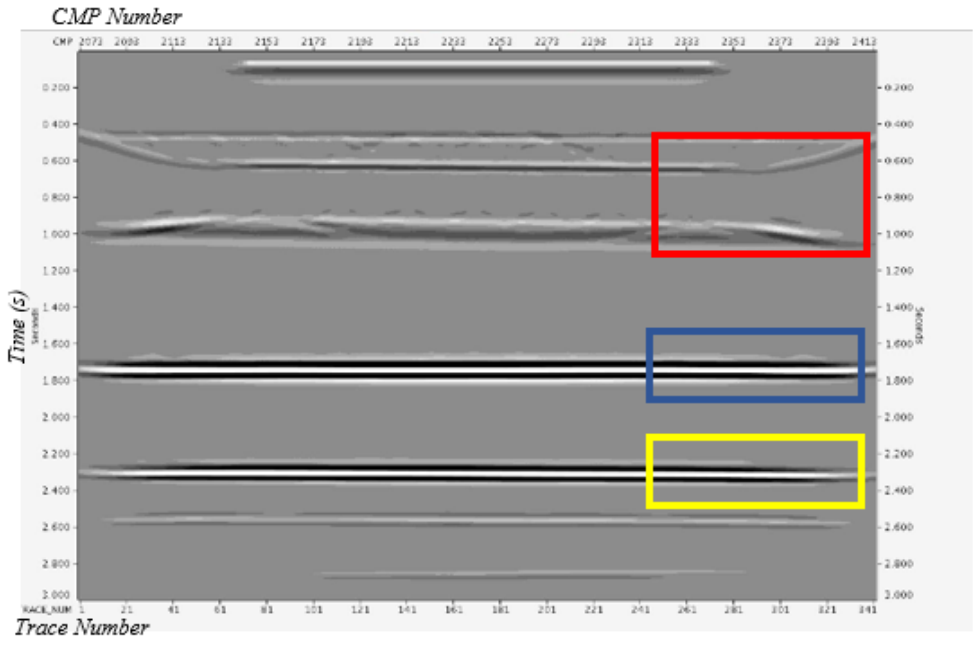

Gambar 7. (Colour Online) Stack Migrasi Kirchhoff

Gambar 7 menunjukkan lapisan pertama (Kotak merah) beresolusi rendah serta tidak menunjukkan perlapisan sesuai model sintetik. Sedangkan untuk reflektor lapisan kedua (Kotak biru) dan ketiga (Kotak kuning) hasil migrasi Kirchhoff sudah bagus dan terlihat perlapisannya. Hal inilah yang menjadi alasan perlunya dilakukan proses migrasi dengan metode anistropi beda hingga dengan memasukkan nilai $\eta$ yang tadi sudah di analisis, nilai $\eta$ dimasukkan dalam bentuk velocity anisotropi dengan nilai $\eta 0,25$.

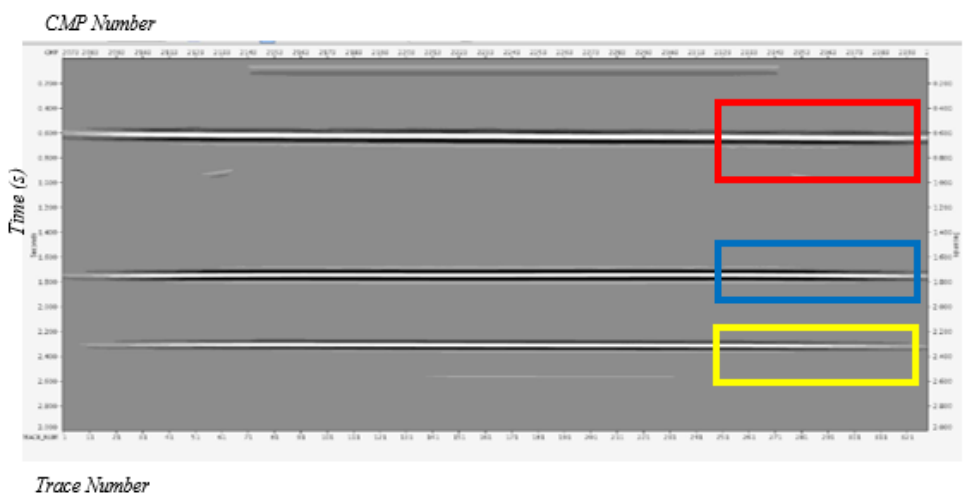

Gambar 7. (Colour Online) Stack Migrasi anisotropi beda hingga 
Berdasarkan gambar 5.10 menunjukkan bahwa hasil migrasi anistropi beda hingga pada lapisan pertama yang mengandung efek anistropi terlihat bagus (mengalami peningkatan resolusi). Hal ini berbeda dengan hasil migrasi Kirchhoff sebelumnya, yakni lapisan pertama beresolusi rendah dan tidak terlihat bentuk perlapisannya.

\section{KESIMPULAN}

Dalam penelitian ini dapat disimpulkan beberapa hal sebagai berikut. Reflektor lapisan pertama dengan kedalaman $500 \mathrm{~m}$ memiliki nilai anistropi sebesar $25 \%(0,25)$, hal ini terjadi karena rasio perbedaan antara kedalaman (d) dengan farr offset (x) lebih dari 3. Migrasi Kirchhoff menghasilkan citra yang beresolusi rendah untuk reflektor lapisan pertama yang mengandung anistropi $25 \%$, akan tetapi untuk lapisan reflektor kedua dan ketiga hasilnya sudah bagus (beresolusi tinggi) sesuai dengan model perlapisan sebenarnya. Hasil citra migrasi anistropi beda hingga (Finite difference anisotropi) untuk reflektor lapisan pertama yang mengandung nilai anistropi sebesar $25 \%(\eta=0,25)$ beresolusi tinggi, dimana letak dan bentuk lapisan pertama sesuai dengan model perlapisan sebenarnya, sedangkan untuk refektor lapisan kedua dan ketiga hasilnya tidak dilakukan proses anistropi beda hingga karena sudah dianggap baik dengan migrasi Kirchhoff.

\section{UCAPAN TERIMAKASIH}

Penulis mengucapkan terima kasih kepada pihak Pertamina UTC dan Bapak Teguh Suroso yang telah berkenan memberikan kesempatan kepada penulis untuk melakukan penelitian.

\section{DAFTAR PUSTAKA}

1 Agustiningsih, Siska. 2013. Pencitraan Bawah Permukaan Dengan Menggunakan Prestack Depth Migration Anisotropi Pada Medium VTI. Jurnal Online UI: Jakarta.

2 Eaton, David W. S. Finite difference traveltime calculation for anisotropic media, gji.oxfordjournals.org/ by guest on June 24, 2015.

3 Fomel, S dan Grecka, V, 2001. Nonhyperbolic reflection moveout of P-wave: An overview and comparison of reasons, Center for wave phenomena. CWP-372

4 Nusantara, Eka, Hernowo Danusaputro dan Nasio Asmoro Hadi. 2005. Aplikasi Migrasi Metode Beda Hingga Pada Pengolahan Data Seismik Untuk Menggambarkan Penampang Bawah Permukaan Yang Sebenarnya. Jurnal Berkala Fisika Undip Vol.8, No.2, April 2005, hal 61-68.

5 Thomsen, L, 1986. Weak elastic anisotropy, GEOPHYSICS. 51, 1954-1966.

6 Yilmaz, Ozdogan, 1987. Seismic Data Processing, Investigation in geophysics (IG2). Hal. 241-334. Society of Exploration Geophysics. 